\title{
Sustainable Ecotourism Development based on Participatory Rural Appraisal: A Case Study of Thekelan Village, Central Java, Indonesia
}

\author{
Pertiwi Andarani ${ }^{1, *}$, Dwi Fitri Lestari ${ }^{1}$, Arya Rezagama $^{1}$, and Sariffuddin Sariffuddin $^{2}$ \\ ${ }^{1}$ Department of Environmental Engineering, Faculty of Engineering, Diponegoro University, Semarang - Indonesia \\ ${ }^{2}$ Department of Urban and Regional Planning, Faculty of Engineering, Diponegoro University, Semarang - Indonesia
}

\begin{abstract}
Thekelan Village, Kopeng District has a special potency of ecotourism. Thekelan Village is located at an altitude of +2000 masl with magnificent scenery and surrounded by protected forest areas. The social characteristics of the community are homogeneous, distinctive, and strong highland culture. Thekelan Village has annually received visits from universities and schools for both comparative study and live-in programs. However, the sustainability of the tourism needed to be evaluated since the community has not participated much in the tourism activity (just lodging and communication). Indicators were established to evaluate the sustainability of existing tourism in Thekelan Village. Moreover, a survey, in-depth interview, and focus group discussion have been conducted to the community to assess the readiness to develop sustainable ecotourism. The results showed that the existing tourism has failed to be sustainable. Nevertheless, the community are ready to implement a new program to improve the management of community participation in the rural tourism setting. Therefore, a sustainable ecotourism can be developed and bring more economic benefits to the local people.
\end{abstract}

Keywords: Thekelan Village; ecotourism; sustainability; indicators; community participation

\section{Introduction}

Thekelan Village is one of the hamlets located in Batur Village, Kopeng Sub-district, Semarang Regency. This hamlet is an area of inclafated territory that is surrounded by the area of Mount Merbabu National Park. Mount Merbabu National Park is a conservation forest area of 5.725 Ha. Communities around the area of Mount Merbabu National Park mostly live as farmers or farm laborers and raising livestock. They work in the area of Mount Merbabu National Park to take grass as a source of fodder and firewood for cooking.

Thekelan village has a very suitable location for tourism where is $2 \mathrm{~km}$ away with Kaseng Wisata Kopeng and Perhutani Tritop Tour. The area of Kopeng has been developed long ago by local government as an agroeconomic tourism destination. Many small hotels are grown on the road to the Kopeng because of its natural beauty, agro-tourism and a cool atmosphere. This location can be an alternative tour of the city of Semarang and Solo Karisidenan area that is now growing rapidly with $40 \mathrm{~km}$ or 1.5 hours drive. By offering the concept of typical living-in village, Thekelan Village has its own advantages due to its location in Kopeng Tourism area. Some of the competitors who set out the object of living-in village tourism for integrated farming and agricultural education are located far away, such as Magelang Regency so it will have its own market segmentation.

In current conditions, Thekelan Village has received several visits from universities and schools for both comparative study and live in programs. However, the problem is that the activity of tourists currently do not involve residents and still focused on enjoying-naturetourism only. The number of tourists who visit each month is also uncertain because it only relies on the partner. The main income of the people of Thekelan Village belongs to the middle to lower class with the profession as farmers and farmers on average reaching Rp 30.000 - Rp 75.000 per family per day. Meanwhile the income from tourists cannot be ascertained every month because it depend on the partner. The absence of a thorough awareness of the importance of tourist villages in improving the economy becomes a challenge in the paradigm shift.

The development of ecotourism with the concept of education in Thekelan Village can potentially increase the welfare of residents. Ecotourism is responsible travel to natural areas which conserves the environment and improves the welfare of the local people [1]. Culture reflecting local wisdom should be developed and integrated into Community Based Tourism (CBT) so that tourists are not only enjoying natural beauty, but also have the opportunity to interact with local people's lifestyles

\footnotetext{
${ }^{*}$ Corresponding author: andarani $@$,ft.undip.ac.id
} 
[2]. Therefore, the study of educational tourism development covering the natural potential and local wisdom of the community is necessary. Revitalizing the community needs to be done. The absence of a thorough awareness of the importance of tourist villages in improving the economy becomes a challenge in the

Table 1. Sustainability Indicators on Ecotourism

\begin{tabular}{|c|c|c|c|c|}
\hline Dimension & No. & Indicator* & Source & Results \\
\hline \multirow[t]{11}{*}{ Social } & 1 & The level of satisfaction & Questionnaire & Favorable \\
\hline & 2 & The decision-making process & Questionnaire & Favorable \\
\hline & 3 & The level of participation & Questionnaire & Favorable \\
\hline & 4 & The social discrepancy & Questionnaire & Unfavorable \\
\hline & 5 & The poverty rate & $\begin{array}{l}\text { Questionnaire } \\
\text { assessment }\end{array}$ & Unfavorable \\
\hline & 6 & The rate of equitable distribution of incomes & Questionnaire & Unfavorable \\
\hline & 7 & The rate of tendency to consumerism & Interview & Unfavorable \\
\hline & 8 & The hospitality rate & Observation & Favorable \\
\hline & 9 & The specific culture existence & Questionnaire & Favorable \\
\hline & 10 & The accessibility of communication and transportation & $\begin{array}{l}\text { Questionnaire and } \\
\text { observation }\end{array}$ & Unfavorable \\
\hline & 11 & The community response to ecotourism & Questionnaire & Favorable \\
\hline \multirow[t]{7}{*}{ Economic } & 1 & The level of income & Questionnaire & Unfavorable \\
\hline & 2 & The level of investment & $\begin{array}{l}\text { Interview } \\
\text { Observation }\end{array}$ & Unfavorable \\
\hline & 3 & The level of local economic support & Questionnaire & Unfavorable \\
\hline & 4 & The rate of financial facilities for people with low income & $\begin{array}{l}\text { Questionnaire and } \\
\text { Interview }\end{array}$ & Favorable \\
\hline & 5 & The tourism impact on the economic aspect & Questionnaire & Unfavorable \\
\hline & 6 & The tourism impact on one family's income & Questionnaire & Unfavorable \\
\hline & 7 & The time when the tourism object affect the economic & Questionnaire & Unfavorable \\
\hline \multirow[t]{14}{*}{ Environment } & 1 & The water resources & Questionnaire & Favorable \\
\hline & 2 & The water quality & Questionnaire & Favorable \\
\hline & 3 & The water quantity & Questionnaire & Favorable \\
\hline & 4 & The sewerage facility existence & Questionnaire & Favorable \\
\hline & 5 & The sewerage facility problem & Questionnaire & Unfavorable \\
\hline & 6 & The soil condition in the last $5-10$ years & Questionnaire & Favorable \\
\hline & 7 & The changes of soil condition due to tourism activity & Questionnaire & Favorable \\
\hline & 8 & The air condition in the last $5-10$ years & Questionnaire & Favorable \\
\hline & 9 & The changes of air condition due to tourism activity & Questionnaire & Favorable \\
\hline & 10 & The environmental problem in the last 10 years & Questionnaire & Unfavorable \\
\hline & 11 & The environmental management program & Questionnaire & Favorable \\
\hline & 12 & The participation to the environmental protection program & Questionnaire & Favorable \\
\hline & 13 & The participation willingness & Questionnaire & Favorable \\
\hline & 14 & The rate of eco-touristic incomes allocation for environment & Questionnaire & Favorable \\
\hline \multirow[t]{4}{*}{ Management } & 1 & The level of local participation & Questionnaire & Favorable \\
\hline & 2 & The level of inter-sectoral cooperation & Interview & Unfavorable \\
\hline & 3 & Accessibility of information and the transparency of programs & $\begin{array}{l}\text { Interview } \\
\text { observation }\end{array}$ & Favorable \\
\hline & 4 & Motivation rate for tourism development & Questionnaire & Favorable \\
\hline
\end{tabular}

*Source: modified from Mosammam et al.

culture to improve the economic condition of the

paradigm shift.

\section{Methods}

\subsection{Participatory Rural Appraisal (PRA)}

Methods of approach with the community using Participatory Rural Appraisal techniques. Workshop that aims to explore and inspire public awareness about educational tourism potential so that people will move with self-help (Community Base Tourism [3]. Community awareness in maintaining the environment such as waste management, waste water, maintaining and loving nature needs to be improved.

\subsection{Sustainability Indicators}

The sustainability indcators were developed according to Mosammam et al.'s study [4]. However, the indicators were modified based on the existing condition in the field because Thekelan Village is not included in the protected area of the government. In this study, the indicators consisted of 4 dimensions, namely social-culture, economy, environment, and management. The details of sustainability indicators chosen can be seen in Table 1. 


\subsection{Structured Survey}

Based on these indicators, structured questionnaires were prepared and distributed among the residents of Thekelan Village. Sixty people were selected in 6 Thekelan Village. The questionnaire had five parts: identity, social-culture, economy, environment, and management. This questionnaire explored the respondents' perceptions of existing tourism development and their readiness to develop sustainable ecotourism.

\section{Results and Discussion}

\subsection{Respondents' Profile}

Based on the results of questionnaire, there were 48 respondents that aged 21 to 50 . This indicates that the majority of respondents is in a productive age. There were 24 female respondents and 36 male respondents. Twentyfive of 60 respondents were elementary school graduates, only 19 middle school graduates, 7 high school graduates, and 2 bachelor degree graduates. The marital status showed that 55 of respondents were married, 3 single, and 2 widower. The interesting fact is that most of the families have more than 5 family members. The occupation of respondents was dominated by farm and industrial workers, namely 41 and 11 respondents respectively. The electricity power used in the Thekelan Village were 450 Watt (47 respondents), 350 Watt (2 respondents), 900 Watt (10 respondents), and 1300 Watt (1 respondents).

\subsection{Sustainability Evaluation of Ecotourism}

Theoretically, ecotourism has many socio-economic and environmental benefits. Nevertheless, globally the literature shows that, in practice, ecotourism has many functions that have many positive and negative impacts generally through its perception, development and planning approach $[5,6]$. Thus, empowering local people by providing skills-related training and involving their participation in all process stages from planning to decision-making are very important to do.

Based on the survey on the sustainability indicators of ecotourism, only one dimension (economy) showed totally almost all unfavourable condition (Fig. 1). There were 6 out of 7 indicators: the level of income, the level of investment, the level of local economic support, the tourism impact on the economic aspect, and the tourism impact on one family's income. As above-mentioned, although the tourism in Thekelan Village has started since 2006, $46 \%$ of respondents did not feel any significant difference on economic condition. Another interesting fact is that the tourism income was not for the residents but for the community as general (official's revenue). Despite there is no significant changes in income after tourism objects were established, financial facilities for people with low income were provided in Thekelan Village. Therefore, a tourism development plan and strategy is needed to develop Thekelan Village masterplan to explore the existing tourism potentials and more structured tourism management. Fifty-four percent respondents stated that the source of capital still comes from the community itself, even though the income of the community itself is still low.

As for the social dimension, 5 of 11 indicators were unfavorable, namely the social discrepancy, the poverty rate, the rate of equitable distribution of incomes, the rate of tendency to consumerism, and the accessibility of communication and transportation (Fig. 2). The social discrepancy that occurs can be proven by the presence of respondents who have an income of Rp 5.000 .000 but there are still respondents who have an income under $\mathrm{Rp}$ 1.000.000. The income of the respondents was from $\mathrm{Rp} 1,000,000$ to $\mathrm{Rp} 2.500 .000$ (53\%) and less than Rp1.000.000 (33\%). Such condition is categorized as in poverty. Although the income is low, the residents have a high social spirit, such as friendliness and mutual cooperation. It can be inferred that the tourism objects in Thekelan Village could not support the financial condition of the residents. The tourism facilities are still lacks on number and quality because the touris management in Thekelan Village is still lacking in the

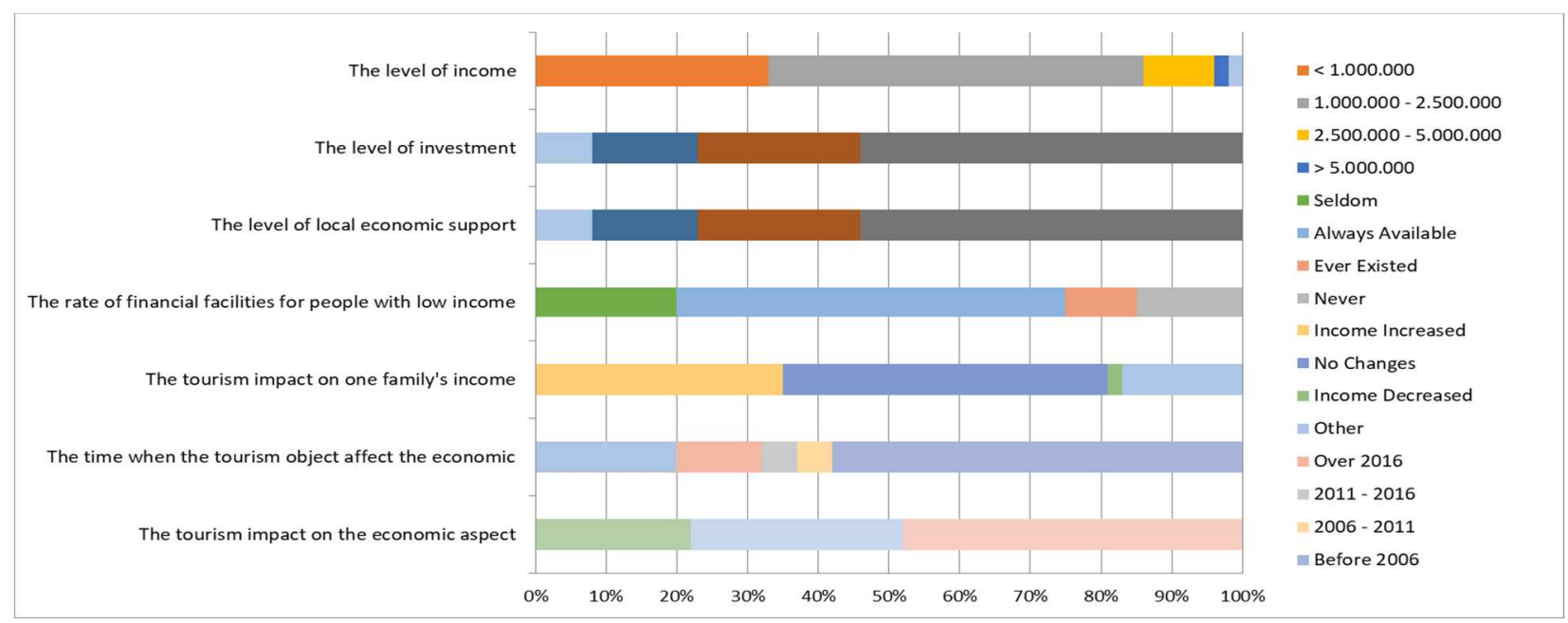

Fig. 1. Percentage Responden in Indicators of Economic Dimension 
knowledge and experience of managing a proper tour. Therefore, it needs a guidance and supervision by certain institutions in the effort to develop tourism so that it can be well structured. In addition, the communication is quite difficult since the cellular phone cannot be used because of the bad signal. This needs to be carried out gradually in strengthening the signal in Thekelan Village and revitalizing the road and adding directions to facilitate transportation to Thekelan Village.

The results of environmental dimension show that it is generally favorable, except two indicators, i.e. the sewerage facility and the environmental problem in the last 10 years (Fig. 3). Since the tourism objects are not still developed properly, there are no significant environmental impacts in Thekelan Village. Examples of environmental problems currently occurring are increasing waste, some of which are still thrown into the nearest river. This is due to the absence of Material Recovery Facilities (TPS), so dry or combustible waste is generally used as a fireplace material. However, the sewerage needs to be developed so that it can function. To overcome this, cooperation with government agencies can be done through coordination of the tourism community in the construction of Material Recovery Facilities (TPS) and improvement of the waste water distribution system, so that it can provide safe and comfortable facilities for tourists in the future. With regards to other waste, such as solid waste and waste water, the community has environmental management program. The programs covers solid waste management concept, such as 3R (Reduce, Reuse, Recycle), vermicomposting, and utilization of cow manure for fertilizer. All of these

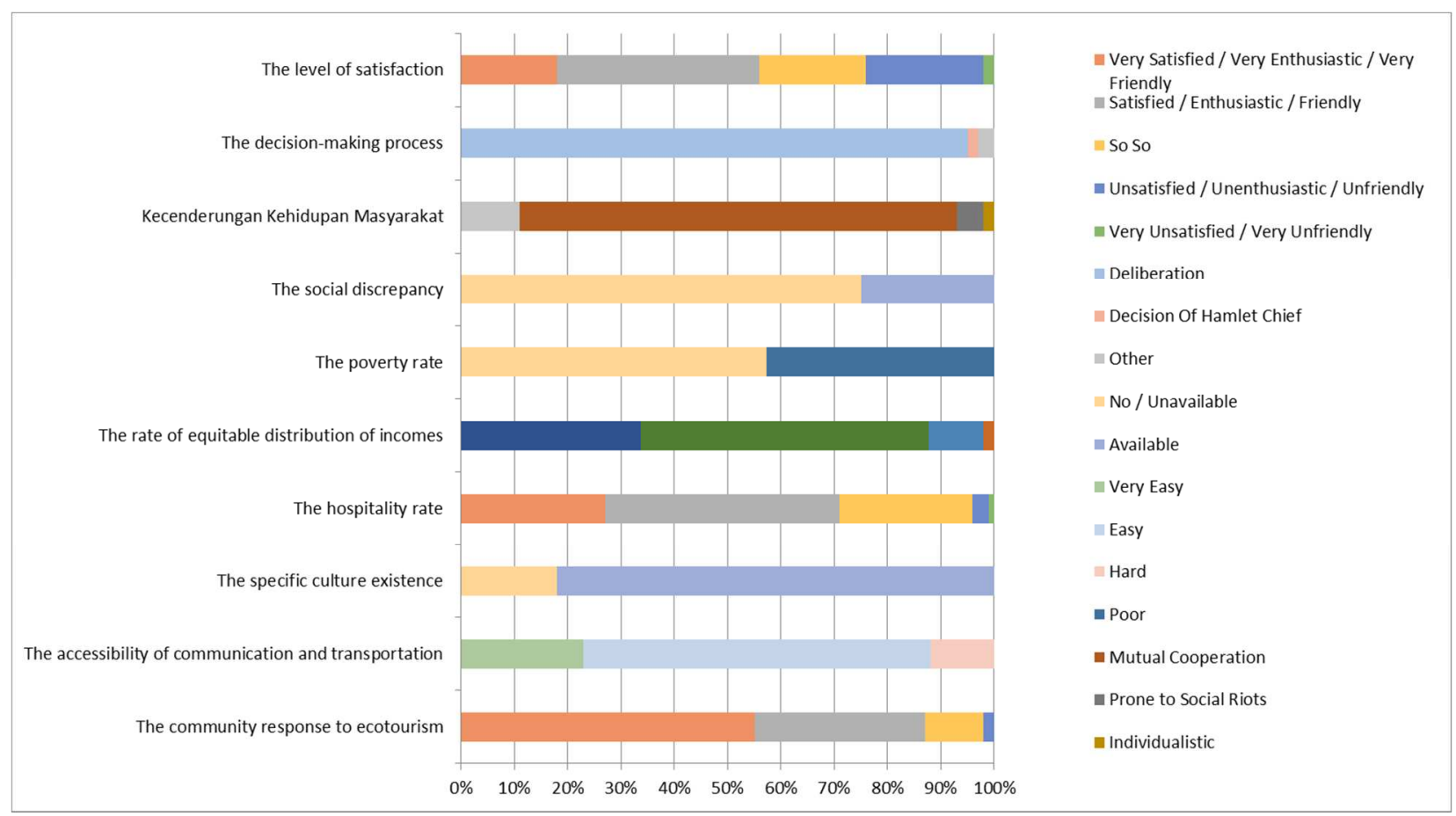

Fig. 2. Percentage Responden in Indicators of Social Dimension

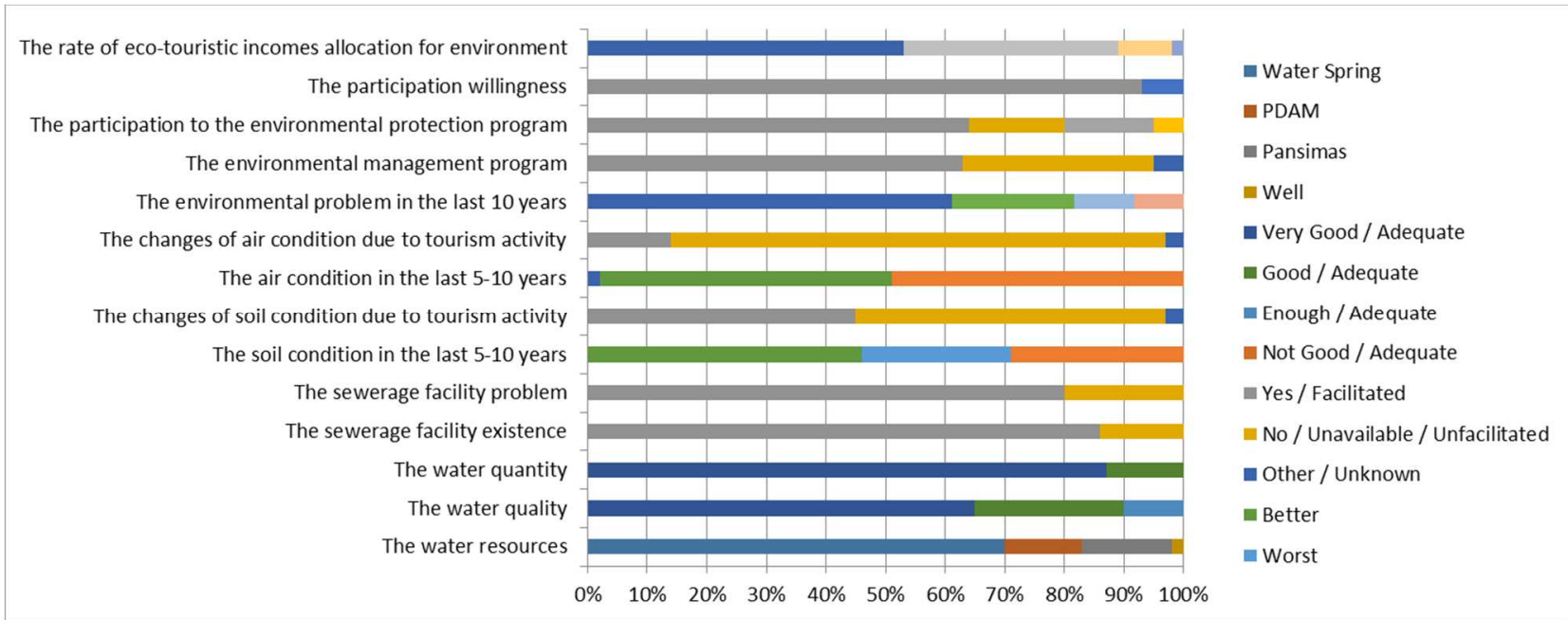

Fig. 3. Percentage Responden in Indicators of Environmental Dimension 


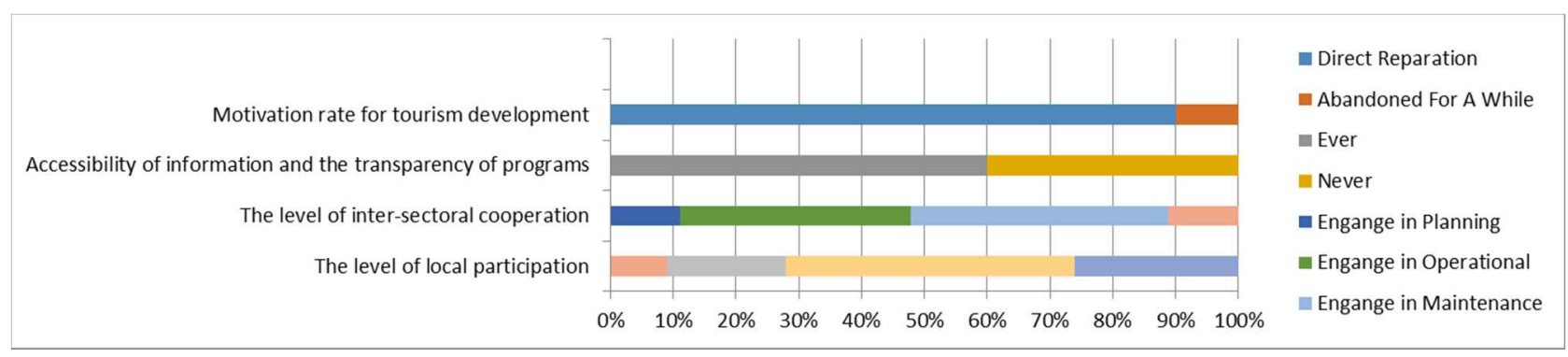

Fig. 4. Percentage Responden in Indicators of Management Dimension

practices will also encourage low carbon society since it involves $3 \mathrm{R}$ so that the carbon emission will be reduced.

The last dimension is the management shown in Fig. 4. Evaluation through survey shows that the existing condition of tourism management was favorable, except the level of inter-sectoral cooperation. This is due to the lack of coordination between the headman and other sectors. Consequently, the main concern here is to assist coordination among government, tourism agency, company, and public to achieve a mutually beneficial common goal. The residents shows the enthusiasm toward the sustainable ecotourism and when a program from school or university was being held, the level of local participation was high $(60 \%)$ according to the questionnaire.

In general, the village leaders and its residents had high motivation and willingness-to-participate in the existing tourism as well as the proposed ecotourism program. Nevertheless, the living-in program and farming tourism should be improved and published to the wider community. As mentioned in Promburon et al's study [7], improvements should be planned for the facilities that were not satisfactory for the tourists. In this case, the facilities include clean bathrooms (and proper sewerage) in the guesthouse, communication aspect (able to use cellular phone), easy-comfortable-safe transportation to the Thekelan Village, farming facility, clean and interesting cattle pens. Ecotourism has the potential of providing economic incentives to preserve natural habits if and only if the revenues are large enough and accessible to the target populations (Colvin, 1994; Fennell, 2008 in Coria and Calfucura [8]). Currently, the local people only involve in lodging and personal communication without an integrated tourism system. While involvement and participation of communities in the tourism industry can be viewed in the decision-making process and in the sharing of tourism benefits, community participation through employment brings more economic benefits directly to the household level [9]. Regular economic gains from formal or informal sector employment and business opportunities empower the community economically. The economic empowerment results in improved infrastructures, health facilities, awareness and education of the locals which in turn empowers them socially [10]. The participatory rural appraisal (PRA) enabled the participants to raise awareness of their own knowledge, to re-evaluate and feel proud of it, giving them a voice that allowed them to actively and autonomously participate in decision-making and the management of their resources and territory [11]. The ecotourism program in Thekelan Village will be socialized through PRA concept such as workshops.

\section{Conclusions}

This study evaluated the tourism development in Thekelan Village using questionnaire (60 respondents). It is concluded that the current tourism in Thekelan Village was not sustainable according to the field survey (questionnaire, observation, and interview). One of the sustainability dimension that has highest unfavourable condition was economic aspect. The development of ecotourism framework in the near future should consider the economic aspect as well as protecting the environment, since the current social aspect has relatively favourable condition.

\section{Acknowledgement}

The authors would like to thank Ministry of Research and Higher Education of Indonesia for the research grant under KKN-PPM Scheme (No.: 1 03-05/tN7 .P4.3 1PM12018) and assistance of all students involved..

\section{References}

1. S. Ashok, H. R. Tewari, M. D. Behera, and A. Majumdar, Tour. Manag. Perspect. 21, 24-41 (2017)

2. B. T. Suroyo and W. Handayani, J. Perenc. Wil. dan Kota 25, 243-261 (2014)

3. T. Budiarti, Suwarto, and I. Muflikhati., J. Ilmu Pertan. Indones. (2013)

4. H. M. Mosammam, M. Sarrafi, J. T. Nia, and S. Heidari, Tour. Manag. Perspect. 18, 168-178 (2016)

5. J. Courvisanos and A. Jain, Tour. Hosp. Plan. Dev. 3(2), 131-142 (2006)

6. H. M. Donohoe and R. D. Needham, J. Ecotourism . 5 (3), 192-210 (2006)

7. T. Promburom, P. Klunklin, and S. Champawalaya, Kasetsart J. (Soc. Sci) 30, 338-346 (2009)

8. J. Coria and E. Calfucura, Ecol. Econ.. 73, 47-55 (2012)

9. S. Prabhakaran, V. Nair, and S. Ramachandran, Procedia - Soc. Behav. Sci. 144, 290-295 (2014)

10. M. Das and B. Chatterjee, Tour. Manag. Perspect. 14, 3-16 (2015)

11. C.S. Lara, A.F. Crispín, M.C.L. Téllez, María, J. Clean. Prod. DOI:10.1016/j.jclepro.2017.08.072 